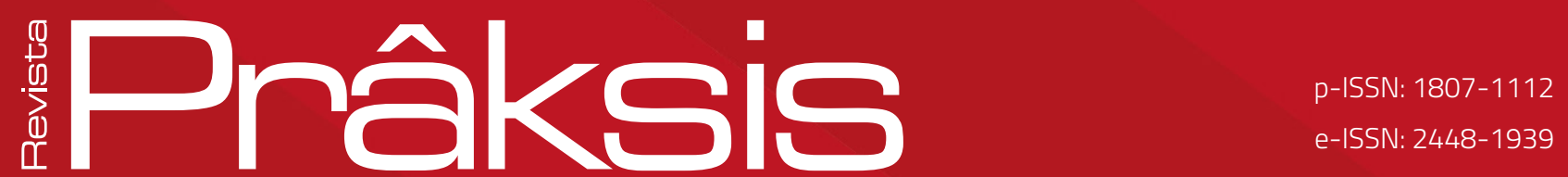

Recebido em: 15 de setembro de 2018 Aprovado em: 10 de fevereiro de 2019 Sistema de Avaliação: Double Blind Review RPR |a. 16 |n. 2 |p. 338-363 | mai./ago. 2019 DOI: https://doi.org/10.25112/rpr.v2i0.1754

\title{
AUTONOMIA dA RELAÇÃO MÉDICO- PACIENTE SOB O ASPECTO DOS CUIDADOS PALIATIUOS: UM ESTUDO NOS Códigos de CONDUTA MÉdICA DO BRASIL E PORTUGAL
}

AUTONOMY OF THE PHYSICIAN-PATIENT RELATIONSHIP UNDER THE PALLIATIVE CARE ASPECT: A COMPARATIVE STUDY IN THE MEDICAL CODES OF CONDUCT IN BRAZIL AND PORTUGAL

\section{Haide Maria Hupffer}

Pós-Doutora em Direito pela Universidade do Vale do Rio dos Sinos (São Leopoldo/Brasil).

Professora na Universidade Feevale (Novo Hamburgo/Brasil).

E-mail: haide@feevale.br.

\section{Cleci Benemann}

Especialista em Saúde do Trabalhador pela Universidade Feevale (Novo Hamburgo/Brasil).

E-mail: clecibenemann@gmail.com. 


\section{RESUMO}

A presente pesquisa tem como objetivo principal apresentar a composição do Código de Ética Médica brasileiro e do Código Deontológico Médico português e traçar um comparativo entre ambos, a partir da apresentação de dois casos médicos, amplamente divulgados na mídia, e da análise de decisões de Tribunais do Brasil e de Portugal, com ênfase na autonomia da relação médico-paciente sob o aspecto dos cuidados paliativos. A pesquisa é de natureza qualitativa, exploratória e descritiva, com utilização do método comparativo, histórico e dialético. As discussões são permeadas com análise documental e jurisprudencial, casos reais e revisão da literatura. Como resultado, verifica-se, a partir da análise dos cuidados paliativos, que a terminalidade da vida desafia o médico, capacitado para salvar vidas, independentemente de sua crença ou ideologia, seja no Brasil ou em Portugal, a um dever de cuidado e de respeito à vontade do paciente. A pesquisa também mostrou que Portugal encontra-se mais avançado que o Brasil em relação aos cuidados paliativos por ter um aparato legal constituído por Resoluções, Portarias e Despachos, em que são normatizadas questões que vão desde instalações específicas até profissionais qualificados para esse fim.

Palavras-chave: Relação médico-paciente. Autonomia. Cuidados Paliativos. Estudo comparado.

\section{ABSTRACT}

The main objective of this research is to present the composition of the Brazilian Medical Code of Ethics and the Portuguese Medical Code of Ethics and draw a comparison between the two, based on the presentation of medical cases widely disseminated in the media, and the analysis of decisions of Courts of Brazil and Portugal, emphasizing the autonomy of the physician-patient relationship under the palliative care aspect. The research is of a qualitative, exploratory and descriptive nature, using the comparative, historical and dialectical methods. The discussions are permeated with documentary and case law analysis, real cases and literature review. As a result, it is verified that, from the analysis of the autonomy in the palliative care, the end-of-life challenges the physicians, who are trained to save lives, regardless of their beliefs or ideologies, to a duty of care and of respect to the patient's will, whether in Brazil or in Portugal. The research also showed that Portugal is more advanced than Brazil regarding the palliative care, since it has a legal framework composed by Resolutions, Ordinances and Clearances, which regulates questions ranging from specific facilities to professionals qualified for this purpose.

Keywords: Physician-patient relationship. Autonomy. Palliative care. Comparative study. 


\section{INTRODUÇÃO}

A profissão médica, seguramente um dos ofícios mais virtuosos e complexos que o homem pode escolher, reveste-se, como pretende mostrar esse trabalho, de um saber-ser e de um saber-fazer extremamente peculiar, de uma natureza jurídica específica e de normativos que norteiam condutas que impactam significativamente na autonomia do paciente em não querer se submeter a tratamento de suporte artificial das funções vitais, em um chamado tratamento fútil e, contudo, receber os cuidados paliativos adequados ao respeito pelo seu direito a uma intervenção global no sofrimento determinado por doença grave ou irreversível, em fase avançada. (LIPPMANN, 2015).

Frente a temática apresentada surge o seguinte questionamento: Quais as semelhanças e diferenças do código de conduta médica determinada pelos códigos brasileiro e português quanto à autonomia da relação médico-paciente sob o aspecto dos cuidados paliativos?

No intuito de responder ao problema de pesquisa este estudo desenvolve-se com o propósito principal de apresentar a composição do Código de Ética Médica brasileiro e do Código Deontológico Médico português e traçar um comparativo entre ambos, a partir da apresentação da decisão de duas cidadãs, amplamente divulgadas na mídia, e da análise de decisões de Tribunais do Brasil e de Portugal, com ênfase na autonomia da relação médico-paciente.

Em relação a seus objetivos o estudo assumirá o nível descritivo. Na pesquisa descritiva analisar-se-ão os códigos de conduta médica do Brasil e de Portugal e as formas como o direito brasileiro e o português convergem ou conflitam no tocante às condutas médicas relativas a autonomia médico-paciente.

A proposta do estudo permite a utilização do método comparativo, histórico e dialético. Casos reais, decisões judiciais e a conflituosidade envolvida quando o paciente decidir que não quer mais se submeter a tratamentos prolongados que ferem a sua dignidade, bem como o agir médico frente aos cuidados paliativos, fornecem a base para a análise dialética. Como técnica de pesquisa será utilizada a pesquisa bibliográfica, documental, jurisprudencial e estudo de caso para análise da relação médicopaciente de casos concretos e uma decisão de um Tribunal brasileiro e outra de um Tribunal português, por amostragem, no tocante a violação desses mesmos códigos.

\section{A CONDUTA DO MÉDICO EM RELAÇÃO AO PACIENTE}

Arelaçãomédico-pacientevem sofrendo alteraçõesao longo dahistória, motivadapor questionamentos em relação à postura mais adequada do médico no que diz respeito ao esclarecimento do paciente. Dúvidas atinentes à necessidade do diagnóstico e do prognóstico serem, ou não, revelados de forma pormenorizada; incertezas no que tange às condutas terapêuticas estarem, ou não, minuciosamente 
compartilhadas com o paciente e; ainda, informações antecederem, ou não, essas condutas, permeiam normatizações nos códigos de conduta médicos. (MUÑOZ; FORTES, 1998, p. 56-58).

Frisando a importância da relação médico-paciente, cita-se como exemplo a Carta Ibero-americana de Ética Médica, editada pelos países integrantes do Foro Ibero Americano de Ética Médica, na qual se comprometem a respeitar os princípios éticos por ela contemplados. Dentre esses, o princípio referente a relação médico-paciente menciona que "Todos los pacientes merecen respeto e igualdad de trato. La relación médico-paciente es la piedra angular de la práctica médica, y la confianza es el elemento esencial en esta relación", simbolizando a importância da confiança nessa relação. (FORO IBEROAMERICANO DE ENTIDADES MÉDICAS, 2013).

O paciente tem o direito de conhecer o seu diagnóstico, a terapêutica e o prognóstico. (PINA, 2013, p. 152-154). No entanto, há de se considerar o bem do paciente, já que aspectos como o quanto a verdade poderá gerar ansiedade e depressão ao doente, como o quanto a fragilidade do paciente impactará no seu caminho dali em diante, ou ainda, ao contrário, o quanto a verdade poderá ser libertadora e benéfica, necessitam de análise. Constata-se que, autores como Beauchamp, Childress (2013) e Valls (2004), enfocam a necessidade do doente em conhecer a verdade, já que, notadamente na maioria das vezes, ele próprio se apercebe da gravidade de sua situação. Contudo, dificuldades na precisão do diagnóstico ou a manifestação do doente em não querer conhecer a verdade devem ser respeitadas. (PINA, 2013, p. 154-156).

No Brasil, o Código de Ética Médica (CFM, 2009), em seu Capítulo V - Relação com pacientes e familiares - aborda uma série de proibições ao médico presentes nessa relação. É vedado ao médico, por exemplo, "desrespeitar o direito do paciente ou de seu representante legal de decidir livremente sobre a execução de práticas diagnósticas ou terapêuticas, salvo em caso de iminente perigo de vida" (artigo 31). O Código, ainda atenta para a proibição de "deixar de informar ao paciente o diagnóstico, o prognóstico, os riscos e os objetivos do tratamento, salvo quando a comunicação direta possa lhe provocar danos, devendo, nesse caso, fazer a comunicação a seu representante legal" (artigo 34). (CFM, 2009). Importante considerar que a informação é um direito do paciente, razão pela qual este pode não querer ser informado, respeitando-se sua vontade. (BELTRÃO, 2014). O código prossegue ressaltando a seriedade do médico em considerar a vontade expressa do paciente ou, em caso de sua impossibilidade, a de seu representante legal (Art. 41, § único). (CFM, 2009).

O chamado "termo de consentimento informado" é o documento hábil que expressa, de forma segura para o médico, a vontade do paciente, uma vez que pressupõe uma "relação dialogante, fato que elimina uma atitude arbitrária ou prepotente do profissional". Interrogações quanto à capacidade 
para consentir, estruturação do termo propriamente dito, adequação vocabular e o processo de obtenção do consentimento informado devem ser prontamente respondidas, atendendo, desse modo, ao respeito à dignidade e à autonomia do paciente. (CLOTET; FRANCISCONI, 2000, p. 13-111). São usuais as terminologias "consentimento informado", "consentimento esclarecido", "consentimento livre e esclarecido" e "termo de consentimento", como observa Pithan (2012, p. 88).

Além da normatização acerca da autonomia do paciente, o Capítulo V do Código de Ética Médica brasileiro destaca a responsabilidade do médico em utilizar-se de todo o conhecimento e de toda a técnica em prol do paciente e o compromisso de atendê-lo em uma situação de urgência ou de emergência. Todos esses aspectos vão ao encontro da vontade do paciente, permeando essa relação de características atinentes aos impactos jurídicos que podem decorrer dessa dinâmica. (CFM, 2009).

Complementando esses aspectos, é imperativo estabelecer a natureza jurídica da relação médicopaciente. No Brasil, a doutrina e os tribunais apontam para uma relação de consumo, normatizada, portanto, pelo Código de Defesa do Consumidor, ou como um contrato atípico que envolve uma relação personalíssima, dependendo do tipo de interação pactuada. (BELTRÃO, 2014). Em Portugal, a doutrina majoritária assevera tratar-se de um contrato civel regido pelo Código Civil Português, sendo a relação médico-doente (PINA, 2013, p. 135) uma relação obrigacional, no entanto, autores como Beltrão (2014) ressaltam que nem todas as situações envolvendo os médicos e seus pacientes assim se enquadrariam, tendo-se como exemplo, os serviços de aborto legalizado e os atendimentos oferecidos em hospitais públicos.

Portanto, tanto no Brasil como em Portugal há uma ambiguidade quanto à natureza jurídica: podese tratar de natureza de consumo ou de natureza contratual. Entretanto, qual a importância desse enquadramento? A partir da definição da natureza jurídica se estabelece a responsabilidade civil do médico, além de outros aspectos jurídicos como prescrição e ônus da prova. Ressalte-se que, o dever de informar está presente na relação médico-paciente, independentemente da natureza jurídica a qual essa relação se subordina. (BELTRÃO, 2014).

Outra característica da responsabilidade civil do médico (e de profissionais liberais, em geral) referese ao tipo de obrigação a que o profissional está vinculado. A responsabilidade civil do médico é subjetiva e decorrente de uma obrigação de meio (artigo $14, \S 4^{\circ}$ do Código de Defesa do Consumidor). Matielo (1998, p. 153) esclarece que:

Obrigação de meios é a que vincula o profissional à aplicação diligente de todos os recursos disponiveis para a melhor condução possível do caso clínico que será alvo de seus préstimos. 0 médico não fica adstrito a um resultado final, mas tem de envidar todos os esforços e utilizar-se dos aparatos técnicos que estiverem razoavelmente ao 
seu alcance. A cura do paciente não é, certamente, o objetivo jurídico da contratação, embora se coloque como finalidade primacial do atendimento prestado. [...] A existência da obrigação de meios é a única solução que pode justificar a liberdade de atuação do profissional de saúde, pois se fosse ele jungido a um resultado específico, fatalmente estaria derrubada até mesmo a teoria da contratualidade nas relações médico/paciente. Na relação que envolve obrigação de meios o objeto do contrato é a atuação zelosa e tecnicamente correta do médico, mantendo-se dentro dos parâmetros apontados pela ciência.

Consequentemente, a relação médico-paciente está alicerçada na busca pelo curar; entretanto, seria uma tarefa impossível o médico se comprometer com a cura definitiva como resultado. (PRETEL, 2010). A jurisprudência brasileira corrobora essa limitação, tal como se verifica no Acórdão do Tribunal de Justiça do Estado de São Paulo ao apregoar que:

\begin{abstract}
Ação de indenização por danos morais e estéticos. Autora que apresentava um quadro de apendicite. Ausência dos sinais característicos da enfermidade. Diagnóstico, no caso, difícil. Ausência de defeito na prestação de serviços pelas rés. Inaplicabilidade, ademais, à atividade médica a responsabilidade civil decorrente do risco (artigo 927, parágrafo único, do Código Civil ${ }^{1}$ ). Arte médica que não é ciência exata. Necessidade, apenas, de que seja dispensado o tratamento adequado, sem garantia de cura. Improcedência da ação reconhecida. Sentença reformada. APELO DO RÉU HOSPITAL SANTA PAULA PROVIDO, PREJUDICADO O RECURSO DA AUTORA. (SÃO PAULO, 2009). (Grifou-se).
\end{abstract}

Portanto, para se imputar responsabilidade ao médico, independentemente do tipo de relação, se faz necessário averiguar se esse profissional agiu com culpa, se não utilizou corretamente de todas as possibilidades da ciência médica na busca da cura, e/ou da reabilitação, ou se não agiu com atenção e zelo no desempenho de suas funções.

\title{
30 CÓDIGO DE CONDUTA MÉDICA BRASILEIRO E PORTUGUÊS COM ÊNFASE NA AUTONOMIA DA RELAÇÃO MÉDICO-PACIENTE
}

A deontologia também conhecida como ética profissional é a ciência dos deveres e determina o que pode ou não fazer o profissional vinculado como membro de determinada categoria profissional.

\footnotetext{
1 Diz o parágrafo único do Artigo 927 do CCB/02: [...] "Parágrafo único. Haverá obrigação de reparar o dano, independentemente de culpa, nos casos especificados em lei, ou quando a atividade normalmente desenvolvida pelo autor do dano implicar, por sua natureza, risco para os direitos de outrem". In: BRASIL. Presidência da República. Lei n 10.406, de 10 de janeiro de 2002 . Institui o Código Civil. Disponível em: <http://www.planalto.gov.br/ccivil_03/Leis/2002/L10406.htm>. Acesso em: 11 mar. 2018
} 
(FORTES, 2007, p. 29-31). Os códigos de conduta norteiam o fazer profissional e, no caso específico da profissão médica, todas as atividades que utilizem o conhecimento que advenha da Medicina, como por exemplo, o ensino e a pesquisa e a administração de serviços de saúde. (GOLDIM, 2010).

As normas emanadas pelos conselhos profissionais têm poder coercitivo estabelecendo sansões a quem descumpri-las. Esse aspecto regulamentar gera críticas de alguns pensadores, pois os códigos são elaborados pelos próprios profissionais que os compõem, revelando, segundo Fortes um "interesse meramente corporativo" que resguardaria os integrantes perante a sociedade, distanciando-se de uma verdadeira reflexão ética. (FORTES, 2007, p. 29-31).

No Brasil, utiliza-se para o código de conduta a terminologia Código de Ética Médica, em Portugal, a nomenclatura escolhida é Código Deontológico Médico.

O Código de Ética Médica foi elaborado pelo Conselho Federal de Medicina (CFM, 2009), agência reguladora que possui abrangência em nível nacional e cuja aderência é obrigatória a todos os médicos que desejam exercer a Medicina e visa, dentre outros objetivos, a "garantia do padrão de serviços prestados à população". O código norteia o fazer médico, resultando sua violação em sansões administrativas, não se furtando, no entanto, o médico de estar sujeito à esfera judicial, cível ou penal. Os códigos de conduta deverão estar de acordo com as normas jurídicas pátrias e, em caso de dissonância, submeterem-se a elas. (FONSECA; FONSECA, 2016, p. 417-418).

O Código de Ética Médica, atualmente em vigor no Brasil, foi aprovado pela Resolução CFM nº 1.931/2009 e está organizado em capítulos e em artigos. Vale ressaltar que há documentos auxiliares ao código: as resoluções, textos com pequenas introduções e alguns parágrafos ou artigos, que podem ser emitidos pelo Conselho Federal ou pelos Conselhos estaduais. (VIANNA, 2006). O código atual se compõe de vinte e cinco princípios, dez normas diceológicas e dezoito normas deontológicas.

O atual código compõe-se de quatorze capítulos, sendo o Capítulo I intitulado de Princípios Fundamentais (inciso I ao XXV), o Capítulo II trata dos Direitos dos Médicos (inciso I ao X), o Capítulo III da Responsabilidade Profissional (artigo $1^{\circ}$ ao 21); o Capítulo IV dos Direitos Humanos (artigo 22 ao 30); o Capítulo V da Relação com Pacientes e Familiares (artigo 31 ao 42); o Capítulo VI da Doação e Transplante de Órgãos e Tecidos (artigo 43 ao 46); o Capítulo VII da Relação entre Médicos (artigo 47 ao 57); o Capítulo VIII da Remuneração Profissional (artigo 58 ao 72); o Capítulo IX do Sigilo Profissional (artigo 73 ao 79); o Capítulo X dos Documentos Médicos (artigo 80 a 91); o Capítulo XI da Auditoria e Perícia Médica (artigo 92 ao 98); o Capítulo XII do Ensino e Pesquisa Médica (artigo 99 ao 110); Capítulo XIII da Publicidade Médica (artigo 111 ao 118) e o Capítulo XIV das Disposições Gerais (inciso I ao IV). (CFM, 2009). 
No Capítulo I - Princípios Fundamentais - observa-se a autonomia como um princípio valoroso. Essa se mostra presente sob dois ângulos: a autonomia do médico e a autonomia do paciente (GOLDIM, 2010). A autonomia do médico em escolher os serviços a serem prestados e a quem os fornecerá, salvo, obviamente, em casos de urgência ou emergência, ou quando sua recusa possa gerar danos à saúde do paciente; e a autonomia do paciente em escolher os procedimentos que mais Ihe pareçam adequados, desde que não conflitem com os ditames da consciência do médico e desde que se mostrem adequados ao caso e cientificamente reconhecidos. (CFM, 2009).

No que tange aos pacientes, o médico tem o direito de "indicar o procedimento adequado ao paciente", cabendo também a ele definir o tempo necessário para se dedicar a cada um, internando-o em hospitais públicos e privados ainda que não faça parte do corpo clínico daquela instituição hospitalar. (FONSECA; FONSECA, 2016, p. 492-493). São todos direitos que vão ao encontro da modernidade ao atualizar informações pertinentes à prática médica, revogando o código anterior que datava de 1988. (CFM, 2009).

O Código de Ética Médica nomeia direitos dos médicos, mas também aponta deveres, ressaltando os impedimentos a que os médicos devem ater-se e disciplina, do capítulo III até o capítulo XIII, questões atinentes à responsabilidade médica, à violação dos direitos humanos, à relação com pacientes e familiares, à doação de órgãos e aos transplantes, à relação entre os médicos, à remuneração profissional, ao sigilo profissional, ao atestado e boletim médico, às auditorias e perícias médicas, ao ensino e pesquisa médica e à publicidade médica. (CFM, 2009).

$\mathrm{O}$ art. $1^{\circ}$ do Capítulo III reforça o dever do médico de utilizar de todo o conhecimento e de toda a técnica em favor de seu paciente, numa clara valorização ao princípio da não maleficência. 0 sigilo médico está disciplinado nos arts. 73 a 79 que proibe ao médico revelar fatos que tenha conhecimento acerca de seu paciente, de revelar aos pais ou representantes fatos relacionados a menores de idade, desde que esses possuam capacidade de discernimento, e de referenciar casos clínicos que possam identificar pacientes, dentre outros. (CPM, 2009).

Outro aspecto que merece destaque no Código de Ética Médica são os chamados cuidados paliativos (GOLDIM, 2010) que foram regulados evitando-se, desse modo, a submissão de pacientes terminais a medidas fúteis ou inúteis. Villas-Bôas pormenoriza o conceito de cuidados paliativos ao apontar questões importantes como a analgesia e a atenção aos familiares:

aqueles cuidados que visam ao conforto do paciente, sem interferir propriamente na evolução da doença e de que são exemplos a analgesia e outras medicações sintomáticas, a higienização, a atenção devida à pessoa e à família naquele momento de dificuldade. (VILLAS-BÔAS, 2008, p. 61-83). 
A revisão e atualização do Código de Ética Médica, ocorrida em 2009 e implementada a partir de abril de 2010, contemplou essa importante visão. Segundo entendimento de Silva e Hortale, os cuidados paliativos são aqueles adotados em fim de vida que objetivem a qualidade de vida do paciente e de seus familiares, praticando diretrizes de cuidados que podem ser ofertados em entidades de saúde ou na residência do paciente (SILVA; HORTALE, 2006). Complementa essa definição os elementos, segundo Sancho, que configuram um doente terminal:

1. Presencia de una enfermedad avanzada, progresiva e incurable

2. Falta de posibilidades razonables de respuesta al tratamento específico

3. Presencia de numerosos problemas o síntomas intensos, múltiples, multifactoriales y cambiantes

4. Gran impacto emocional en paciente, familia y equipo terapéutico, muy relacionado con la presencia, explícita o no, de la muerte

5. Pronóstico de vida inferior a 6 meses. (SANCHO, 2000, 54-61).

Observa-se a partir dessa abordagem, que, embora o médico deva atuar no sentido de identificar tais aspectos que caracterizam uma doença terminal e respeitar a autonomia do paciente, esse profissional, ao longo de sua formação, não foi capacitado para esse comportamento, pois o enfoque sempre foi o de salvar vidas. (SANCHO, 2000, 54-61).

O Código de Ética Médica brasileiro faz referência a esse último estágio de cuidados proibindo em seu regulamento o médico de "abreviar a vida do paciente, ainda que a pedido deste ou de seu representante legal", ressaltando que:

\section{Capítulo V. [...]}

Art. 41. Nos casos de doença incurável e terminal, deve o médico oferecer todos os cuidados paliativos disponiveis sem empreender ações diagnósticas ou terapêuticas inúteis ou obstinadas, levando sempre em consideração a vontade expressa do paciente ou, na sua impossibilidade, a de seu representante legal. (CFM, 2009).

O Código Deontológico Médico português sofreu sua última atualização, a exemplo do código brasileiro, em 2009. Está organizado em seções, capítulos e artigos, sendo composto por sete títulos e esses subdivididos em capítulos. Inicia com o Título I mencionando as "Disposições Gerais", nas quais há quatro subdivisões que discutem os Princípios Gerais (Capítulo I), os Deveres dos Médicos (Capítulo II), a Publicidade (Capítulo III) e os Consultórios Médicos (Capítulo IV). O Título II intitulado "O médico ao serviço do doente", por sua vez, se desdobra em quinze capítulos que abordam no Capítulo I - a Qualidade dos cuidados médicos, no Capítulo II - O início da vida, no Capítulo III - O fim da vida, no Capítulo IV Transplante de órgãos e tecidos humanos, no Capítulo V - Procriação medicamente assistida, no Capítulo 
VI - Esterilização, no Capítulo VII - Intervenções no genoma humano, no Capítulo VIII - Transexualidade e disforia de género, no Capítulo IX - Os médicos e os indivíduos privados de liberdade, no Capítulo X Experimentação humana, no Capítulo XI - Segredo médico, no Capítulo XII - Telemedicina, no Capítulo XIII - Atestados médicos, no Capítulo XIV - Processos clínicos e no Capítulo XV - Honorários. (PORTUGAL, 2009).

Na continuidade, o Código traz em seu Título III - O médico ao serviço da comunidade e aborda no Capítulo I as "Responsabilidades do médico perante a comunidade e no Capítulo II "O médico perito". 0 Título IV alude às "Relações entre médicos". A Secção I cita os "Exames e terapêuticas especializados". O Título V "Relações dos médicos com terceiros" expõe no Capítulo I - Relações com estabelecimentos de cuidados médicos, no Capítulo II - Relações com outros profissionais de saúde e no Capítulo III as Relações com a indústria farmacêutica ou outras. O Título VI se refere à Responsabilidade disciplinar e, por fim, o Título VII das "Disposições finais e transitórias". (PORTUGAL, 2009).

A partir da análise do Código Deontológico Médico torna-se importante também a abordagem acerca do sigilo médico ou segredo médico, como denomina o Código Deontológico. A esse respeito, o Tribunal de Relação de Évora condenou à indenização uma médica que teria violado esse dever do médico e direito do paciente. A Relatora Juíza Maria Isabel Duarte faz alusão que "no exercício ou fora do exercício e no comércio da vida, eu vir ou ouvir, que não seja necessário revelar, conservarei como segredo" reportando-se ao exercício da profissão médica, a partir de Hipócrates, e arrolando o Art. 195 do Código Penal português que preceitua: "Quem, sem consentimento, revelar segredo alheio de que tenha tomado conhecimento em razão do seu estado, ofício, emprego, profissão ou arteé punido com pena de prisão [...]" referindo a proibição ao médico de violar sigilo de paciente. (PORTUGAL, 2014).

Ainda que o Acórdão mencione a violação ao Código Penal, mas não assinale violação ao Código Deontológico Médico português, o segredo médico está preconizado no Capítulo XI do referido dispositivo regulamentador da profissão médica naquele país. O Art. 89 apregoa que "O segredo médico é condição essencial ao relacionamento médico-doente, assenta no interesse moral, social, profissional e ético, que pressupõe e permite uma base de verdade e de mútua confiança" numa diretriz da relação médicopaciente similar à do Brasil. (PORTUGAL, 2014).

No tocante aos cuidados paliativos Portugal avançou em relação ao Brasil. Em 2012 foi criada a Lei $n$. $52 / 2012$ que dispõe sobre o direito e acesso dos cidadãos portugueses aos cuidados paliativos, atribui as responsabilidades do Estado e cria a Rede Nacional de Cuidados Paliativos. Nessa Lei o Estado português definiu cuidados paliativos, distinguindo-os das ações paliativas: 
a) «Cuidados paliativos» os cuidados ativos, coordenados e globais, prestados por unidades e equipas específicas, em internamento ou no domicílio, a doentes em situação em sofrimento decorrente de doença incurável ou grave, em fase avançada e progressiva, assim como às suas famílias, com o principal objetivo de promover o seu bem-estar e a sua qualidade de vida, através da prevenção e alívio do sofrimento físico, psicológico, social e espiritual, com base na identificação precoce e do tratamento rigoroso da dor e outros problemas físicos, mas também psicossociais e espirituais;

b) «Ações paliativas» as medidas terapêuticas sem intuito curativo, isoladas e praticadas por profissionais sem preparação específica, que visam minorar, em internamento ou no domicílio, as repercussões negativas da doença sobre o bem-estar global do doente, nomeadamente em situação de doença incurável ou grave, em fase avançada e progressiva. (PORTUGAL,2012a).

Na sequência a Lei menciona os direitos dos pacientes abrangidos por ela (do art. $1^{\circ}$ ao $\operatorname{art} .4^{\circ}$ ). Observase, em comparação ao Brasil uma evolução, não só pela primeira unidade de cuidados paliativos criada em 1994, mas pela regulamentação legal em 2012. A lei propicia direito ao paciente de escolher o local onde deseja ser tratado, de ser acompanhado nos casos desses mesmos cuidados e, ainda, oportuniza aos tutelados serem ouvidos e acolhidos em suas escolhas pelos médicos.

A Lei 52/2012 de Portugal sofreu alterações em 2015, pela Portaria n. ${ }^{\circ}$ 340/2015, que estabeleceu regras na esfera da Rede Nacional de Cuidados Paliativos - RNCP - delineando e caracterizando as equipes especializadas e determinando os requisitos das instalações de atendimento. (PORTUGAL, 2015). Portugal demonstra, desse modo, adotar políticas ao encontro dessas "carências de longa duração". Na sequência, a Portaria 75/2017 de 22 de fevereiro de 2017, que altera e atualiza a Portaria 340/2015 e que solidifica os cuidados paliativos ao regular a figura dos profissionais de saúde específicos para esse atendimento, posiciona em seu art. $1^{\circ}$, inciso 4 que o corpo de profissionais que vão integrar as UCPRNCCI devem ter "formação específica em cuidados paliativos" e que a direção técnica dever ser exercida por um "médico com formação e experiência reconhecida em cuidados paliativos". (PORTUGAL, 2017a).

Complementam ainda o estudo da legislação portuguesa sobre cuidados paliativos o Despacho n. ${ }^{\circ}$ 14.311-A/2016, de 28 de novembro de 2016, que "aprova o Plano Estratégico para o desenvolvimento dos Cuidados Paliativos para o biénio 2017/2018" referindo que Portugal adota regularmente planejamento estratégico em cuidados paliativos (PORTUGAL, 2016) e a Resolução da Assembleia da República n. ${ }^{\circ}$ 5/2017, de 04 de janeiro de 2017, que determina no Art. $1^{\circ}$ que "Implemente a formação pré-graduada obrigatória em medicina paliativa nas faculdades de Medicina portuguesas, de acordo com as recomendações para esta área e em moldes a fixar", numa alusão à preocupação em formar, em nível de graduação, profissionais habilitados a atuarem em cuidados paliativos. (PORTUGAL, 2017b). 
Ratifica a vontade portuguesa em olhar para os doentes terminais o Aviso n. ${ }^{\circ}$ 15.263/2017, de 19 de dezembro de 2017, que comunica a abertura de concurso para duas vagas para o ciclo de estudos especiais de Cuidados Paliativos no Adulto, a iniciar no ano 2018, pois "se considera que uma condição necessária para a boa prática da medicina paliativa é a formação sólida dos médicos". Assumir "um papel de enorme relevo enquanto processo suplementar de formação dos médicos em matérias e técnicas individualizadas e específicas" é, dentre outros estudos, o que o ciclo pretende. (PORTUGAL, 2017c).

De acordo com a Organização Mundial de Saúde (OMS), "anualmente, mais de 40 milhões de pessoas necessitam de Cuidados Paliativos em todo o mundo", portanto a promoção de "modelos de cuidados paliativos" alinhados aos sistemas de saúde é considerada pela OMS "uma responsabilidade ética de cada Estado" (OMS apud PORTUGAL, 2016), constatando-se pelo estudo retratado que Portugal mantem um avanço relevante em relação ao Brasil.

Ao analisar-se a Lei, o Decreto-Lei e as Portarias implementadas em Portugal observa-se todo um aparato constituído em torno dos cuidados paliativos, desde instalações específicas a profissionais qualificados para esse fim. Além disso, os cuidados continuados integrados demonstram a preocupação do Estado português com o envelhecimento da população e, consequentemente com políticas públicas que amparem pessoas com doenças crônicas incapacitantes, pessoas idosas com dependência funcional e de pessoas com doenças incuráveis em final de vida.

\section{CUIDADOS PALIATIVOS: UM OLHAR SOBRE A VONTADE DE ANA BEATRIZ CERISARA E ANA CATARINA}

Na sequência aspectos da relação médico-paciente sob o ângulo da autonomia nos cuidados paliativos, em ambos os países, serão comparados. As discussões serão permeadas com análise da jurisprudência, casos reais e revisão da literatura. Para introduzir o tema, também serão examinados pontos como a diferença entre eutanásia, ortotanásia e a distanásia, bem como o conceito de testamento vital e sua previsão no Brasil e em Portugal.

\subsection{EUTANÁSIA, ORTOTANÁSIA E A DISTANÁSIA}

A autonomia do paciente em decidir se quer continuar a submeter-se a tratamentos dolorosos e prolongar artificialmente a vida sem que a medicina consiga oferecer expectativa de cura ou, por outro lado, ter o direito de morrer com dignidade são temáticas atuais que também tem demandado considerações.

A vida é direito inviolável tanto na Constituição Federal brasileira quanto na Constituição da República portuguesa. No entanto, um questionamento se faz presente: a vida é direito inviolável, mas seria um 
dever irrenunciável? (SANCHO, 2000). Os avanços da medicina e da biotecnologia contribuíram para que a população tenha maior longevidade, o que também vem concorrendo para discussões e reflexões sobre os cuidados em final de vida.

Sancho (2000, p. 57-60) aponta que "Todos estos avances han generado en la sociedad una especie de delirio de inmortalidad, otorgando al médico una sabiduría, omnipotencia y omnisapiencia que, lógicamente, no posee", numa clara alusão às decisões dos médicos à revelia do que seu paciente deseja.

O Código de Ética Médica brasileiro garante ao paciente o respeito à autonomia da tomada de decisões, como se observa no capítulo I, inciso XXI:

No processo de tomada de decisões profissionais, de acordo com seus ditames de consciência e as previsões legais, o médico aceitará as escolhas de seus pacientes, relativas aos procedimentos diagnósticos e terapêuticos por eles expressos, desde que adequadas ao caso e cientificamente reconhecidas. (CFM, 2009).

Nesse debate faz-se necessária uma contextualização importante no que se refere à eutanásia, ortotanásia e a distanásia. Assim, "de modo geral, pode-se dizer que a eutanásia é a morte antes de seu tempo, a distanásia é, por sua vez, a morte depois do tempo; e a ortotanásia é a morte no tempo certo". Essa é a caracterização que adota Villas-Bôas (2008, p. 65) em relação às medidas em final de vida.

Os conceitos para a eutanásia não são precisos. Para a Associação Médica Mundial "eutanásia é o ato de deliberadamente terminar com a vida de um paciente, mesmo com a solicitação do próprio paciente ou de seus familiares próximos". (AMM, 1987). Diferentemente de alguns países europeus como a Holanda e a Bélgica, em Portugal a eutanásia é proibida, do mesmo modo no Brasil. Por outro lado, a distanásia, também chamada de "obstinação terapêutica" ou "futilidade médica", trata da prorrogação exagerada da morte de um paciente terminal ou o prolongamento a qualquer preço, ainda que "cause sofrimento bárbaro ao paciente". Isso porque a distanásia "é a morte lenta e com muito sofrimento". A distanásia é o oposto da ortotanásia. (BOTTEGA; CAMPOS, 2018). A ortotanásia, proveniente dos radicais gregos orthos (reto, correto) e thanatos (morte), numa alusão à morte no seu tempo certo, visa fornecer um conforto ao paciente terminal (cuidados paliativos) deixando que a vida siga seu curso natural e que a morte chegue na hora certa, sem prolongamentos desnecessários, evitando medidas fúteis que só causariam dor e sofrimento. (JUNGES, 2010, p. 275-288). Inúmeras vezes o paciente necessita de medicamentos para aliviar a dor e, sob esse ponto de vista, observa-se claramente o que preceitua a ortotanásia, já que "a dose não deve ser tal que torne a morte uma certeza imediata, mas a menor possível para a produção da analgesia". Esse aspecto é bem importante, pois delimita a atuação dos profissionais de saúde no que tange a uma atuação lícita. (VILLAS-BÔAS, 2008, p. 62-63). 
O Código de Ética Médica brasileiro, manifesta-se, nessa direção, no Capítulo V - Relação com pacientes e Familiares, vedando ao médico:

Art. 41. Abreviar a vida do paciente, ainda que a pedido deste ou de seu representante legal. Parágrafo único. Nos casos de doença incurável e terminal, deve o médico oferecer todos os cuidados paliativos disponíveis sem empreender ações diagnósticas ou terapêuticas inúteis ou obstinadas, levando sempre em consideração a vontade expressa do paciente ou, na sua impossibilidade, a de seu representante legal. (CFM, 2009).

Na ortotanásia, os cuidados paliativos são fundamentais uma vez que não se trata de interrupção voluntária da vida, e sim, do respeito à evolução natural do processo de morte e, também, do respeito às decisões do paciente. Esse respeito em final de vida foi ratificado em Madrid, em 1987, na Declaração sobre Eutanásia. (CASADO; ROYES, 2003).

As vontades e os desejos do paciente, também conhecidas como diretivas antecipadas de vontade, podem ser expressos por intermédio do chamado testamento vital, que é "uma declaração de um cidadão mostrando, nos casos em que se atinge a terminalidade da vida, em doenças crônicas ou acidentes graves sem possiblidade de recuperação, quais são os tratamentos que este deseja receber quando a morte se aproxima". Dito de outro modo, o paciente pode deixar em uma diretiva antecipada de vontade se deseja que sejam ministrados "tratamentos paliativos, que tragam conforto, ou os agressivos e intervencionistas, e quais as medidas de suporte vital que entende serem cabíveis nestas condições". 0 testamento vital "deve ser seguido mesmo quando aquele que recebe o tratamento estiver inconsciente e não conseguir mais se comunicar com o médico" (LIPPMANN, 2015).

O testamento vital tem reconhecimento no Brasil, a partir da Resolução n. 1.995 na Ação Civil Pública e do Enunciado 37, aprovado na Plenária da I Jornada de Direito da Saúde do Conselho Nacional de Justiça, em 15 de maio de 2014. Tais normativos legitimam-no ainda que não haja, até o momento, legislação específica atinente a ele. 0 Enunciado 37 assim posiciona:

Enunciado 37: As diretivas ou declarações antecipadas de vontade, que especificam os tratamentos médicos que o declarante deseja ou não se submeter quando incapacitado de expressar-se autonomamente, devem ser feitas preferencialmente por escrito, por instrumento particular, com duas testemunhas, ou público, sem prejuízo de outras formas inequívocas de manifestação admitidas em direito. (LIPPMANN, 2015).

Corrobora esse entendimento o Código de Ética Médica quando refere que "nas situações clínicas irreversíveis e terminais, o médico evitará a realização de procedimentos diagnósticos e terapêuticos 
desnecessários e propiciará aos pacientes sob sua atenção todos os cuidados paliativos apropriados", reiterando a necessidade do médico em lhe respeitar a autonomia e em lhe proporcionar conforto em final de vida. (CFM, 2009).

A exemplo do Brasil, as diretivas antecipadas de vontade, em Portugal (2012b) devem ser expressas por escrito. Elas podem ser feitas em cartório, como aqui, ou incluídas em um banco de dados de testamentos vitais com validade de cinco (05) anos - o Registro Nacional do Testamento Vital - RENTEV. As diretivas antecipadas de vontade podem abranger os seguintes aspectos ao outorgante:
a) Não ser submetido a tratamento de suporte artificial das funções vitais;
b) Não ser submetido a tratamento fútil, ou desproporcional ao seu quadro clínico e de acordo com as boas práticas profissionais, nomeadamente no que concerne às medidas de suporte básico de vida e às medidas de alimentação e hidratação artificiais que apenas visem retardar o processo natural de morte;
c) Receber os cuidados paliativos adequados ao respeito pelo seu direito a uma intervenção global no sofrimento determinado por doença grave ou irreversivel, em fase avançada;
d) Não ser submetido a tratamentos que se encontrem em fase experimental;
e) Autorizar ou recusar a participação em programas de investigação científica ou ensaios clínicos. (LIPPMANN,2015).

Considerando que, em terras lusitanas, o médico tem acesso a esse banco de dados, por meio de uma certificação digital, Lippmann (2015) sugere que o Brasil poderia adotar essa mesma normatização, resguardando desse modo eventual judicialização do médico que respeita a autonomia do paciente em casos de familiares cujas decisões não correspondam com a vontade do paciente.

Realizada esta síntese sobre a diferença entre eutanásia, distanásia e ortotanásia e apresentada a compreensão sobre testamento vital, passar-se-á na sequência a descrever a decisão de Ana Beatriz Cerisara.

\subsection{CUIDADOS PALIATIVOS - ANA BEATRIZ CERISARA E ANA CATARINA}

Um dos casos brasileiros mais emblemáticos, que evidenciam o direito ao paciente de se negar a procedimentos invasivos e dolorosos, é o da gaúcha Ana Beatriz Cerisara de 60 anos, doutora em Educação pela Universidade de São Paulo (USP), com 15 anos de luta contra o câncer. Ana Bea, como era chamada, recentemente decidiu que não iria mais se submeter a nenhum procedimento que lhe causasse dor ou sofrimento. Ela esteve internada por longo tempo numa unidade de terapia intensiva, o que the causou muito sofrimento (CERISARA, 2017). 
Ana Bea, corajosamente, negou-se a morrer assim e preparou-se para a morte organizando a sua vida. Nas palavras dela "eu quero ficar na vida, mas eu não quero ficar na vida a qualquer preço". Desse modo, ela decidiu que não se submeteria a uma cirurgia que poderia redundar em retirada do intestino, pois disse que gostaria de "poder comer", numa menção aos prazeres da vida. (CERISARA, 2017).

Ela segue em seu depoimento, dizendo que "assim como a gente gesta o nascimento, eu estou gestando a minha morte" em alusão ao seu desejo de não sofrer intervenções inúteis. Para ela, "a boa morte é a boa vida" que ela estava vivendo em sua casa, junto com as pessoas e as coisas que amava e, principalmente, sem sentir dor. (CERISARA, 2017). O Conselho Federal de Medicina (2009), em respeito a vontade de pacientes como Ana Bea, regulamentou a ortotanásia por meio da Resolução 1.805/2006, incluiu em 2009 os cuidados paliativos no Código de Conduta Médica no art. 41, do capítulo V e, ratificou essa matéria em 2012, por meio da Resolução CFM n 1.995/2012, que dispôs sobre as diretivas antecipadas de vontade dos pacientes. (CFM, 2012).

O Poder Judiciário também vem se posicionando sobre o tema. Neste sentido, os julgados do Tribunal de Justiça do Rio Grande do Sul (TJRS) apresentados a seguir legitimam o disciplinado pelo CFM e apresentam-se em consonância com a decisão de Ana Bea: Trata-se da Apelação Cível nº 70042509562 e do Agravo de Instrumento $n^{\circ} 70065995078$.

A Apelação Cível interposta pela Associação dos Funcionários Públicos do Estado do Rio Grande do Sul - AFPERGS, entidade mantenedora do Hospital Ernesto Dornelles, localizado no município de Porto Alegre, contra os apelados Gilberto de Oliveira Freitas e Guilherme da Silva Benites, respectivamente filho e neto de Irene Oliveira de Freitas, que fora internada no hospital com indicação de hemodiálise, alude aos desejos da paciente e familiares em caso de gravidade na saúde, (RGS, 2011) como se observa:

CONSTITUCIONAL. MANTENÇA ARTIFICIAL DE VIDA. DIGNIDADE DA PESSOA HUMANA. PACIENTE, ATUALMENTE, SEM CONDIÇÕES DE MANIFESTAR SUA VONTADE. RESPEITO AO DESEJO ANTES MANIFESTADO. [...]. O desejo de ter a "morte no seu tempo certo", evitados sofrimentos inúteis, não pode ser ignorado, notadamente em face de meros interesses econômicos atrelados a eventual responsabilidade indenizatória. No caso dos autos, $a$ vontade da paciente em não se submeter à hemodiálise, de resultados altamente duvidosos, afora o sofrimento que impõe, traduzida na declaração do filho, há de ser respeitada, notadamente quando a ela se contrapõe a já referida preocupação patrimonial da entidade hospitalar que, assim se colocando, não dispõe nem de legitimação, muito menos de interesse de agir.(RGS, 2011). (Grifou-se).

O desejo de ter "a morte no seu tempo certo, não se justificando prolongar um sofrimento desnecessário, em detrimento à qualidade de vida do ser humano", arguido pelo Relator Desembargador 
Armínio José Abreu Lima da Rosa (RGS, 2011) corrobora o defendido por Ana Beatriz Cerisara em sua entrevista.

Na mesma seara, o recurso de agravo de instrumento, interposto pela Fundação Hospital Centenário, do município de São Leopoldo/RS, contra o agravado José Marcos Freitas de Souza, trata de pedido liminar em que a instituição de saúde busca autorização para realizar procedimento cirúrgico, de extrema urgência, já que o paciente e sua madrasta negaram-se a autorizá-lo. Embora considerando pertinente a preocupação do hospital, o juízo a quo indeferiu o pedido, decisão essa mantida em $2^{\text {a }}$ instância, por decisão monocrática e, também, no pedido de reconsideração, como pode ser observado na ementa (RGS, 2013):

1. 0 direito à vida previsto no artigo $5^{\circ}$ da Constituição Federal não é absoluto, razão por que ninguém pode ser obrigado a se submeter a tratamento médico ou intervenção cirúrgica contra a sua vontade, não cabendo ao Poder Judiciário intervir contra esta decisão, mesmo para assegurar direito garantido constitucionalmente. 2. Ademais, considerando que "não se justifica prolongar um sofrimento desnecessário, em detrimento à qualidade de vida do ser humano", o Conselho Federal de Medicina (CFM), publicou a Resolução n 1.995/2012, ao efeito de dispor sobre as diretivas antecipadas de vontade do paciente, devendo sempre ser considerada a sua autonomia no contexto da relação médico-paciente. 3. Hipótese em que o paciente está lúcido, orientado e consciente, e mesmo após Ihe ser explicado os riscos da não realização do procedimento cirúrgico, este se nega a realizar o procedimento, tendo a madrasta do paciente, a seu pedido, assinado termo de recusa de realização do procedimento em questão, embora sua esposa concorde com a indicação médica. 4. Por essas razões, deve ser respeitada a vontade consciente do paciente, assegurando-lhe o direito de modificar o seu posicionamento a qualquer tempo, sendo totalmente responsável pelas consequências que esta decisão pode lhe causar. NEGADO SEGUIMENTO AO RECURSO. (RGS, 2013).

O Relator Desembargador Sergio Luiz Grassi Beck afirma que o paciente tem o direito de decidir se deseja, ou não, se submeter a determinado tratamento médico ou intervenção cirúrgica. De referir que esse aspecto, recorrente nos julgados, trata do direito à vida previsto no artigo $5^{\circ}$ da Constituição Federal, direito esse, segundo os magistrados, "não absoluto, donde se observam dois desdobramentos - ninguém é obrigado a se submeter a tratamento médico ou intervenção cirúrgica contra a sua vontade - e não cabe ao estado intervir contra esta decisão", reforçando o respeito à autonomia dos pacientes. (RGS, 2013).

O caso Ana Bea ganhou notoriedade ao trazer à tona essa temática: o desejo de não se submeter a uma intervenção cirúrgica que Ihe limitaria muito o viver. 0 direito à vida não é absoluto e escolher uma boa morte, com o propósito de optar por cuidados que tragam conforto em final de vida é direito de cada 
um. Ana Bea se manifesta dizendo que seu intuito é o de que "possa de alguma forma contribuir", com outros pacientes em situação semelhante, na acepção de que ela está optando por seguir o curso normal da vida. Nas palavras dela é como se fosse, "um toque de amor à fraqueza, porque ter três tumores, ter uma bolsa de colostomia, ter intestino curto, estar morrendo e não ter dor, para mim é a confirmação de que está dando certo", pois morrer não significa fracassar. (CERISARA, 2017). As palavras de Ana Bea estão em consonância com o que preconiza a humanização da medicina, a partir dos cuidados paliativos e da autonomia do paciente. Ana Bea morreu como desejava, sem dor, no conforto de sua casa, no dia 29 de março de 2018.

Portanto, os estudos na busca de conhecimento e implementação permanente dos cuidados paliativos, as diretrizes do Conselho Federal de Medicina, bem como os julgados brasileiros denotam estarem harmonizados em relação ao respeito à autonomia do paciente em escolher se submeter ou não a determinado tratamento. $O$ respeito aos desejos do paciente é medida que deve ser seguida pelos profissionais de saúde, ainda que o paciente não possa mais exercer seu desejo como outrora o tenha manifestado.

No mesmo sentido do decidido por Ana Bea, outra Ana, desta vez Catarina, em Portugal, também decidiu que não queria se submeter a tratamentos inúteis. Seu marido escreveu o seguinte texto:

\footnotetext{
Apesar de dispor do melhor da medicina, a Ana Catarina recusou passar o tempo que the restava metida em consultórios e hospitais e, muito menos, a ficar permanentemente drogada com analgésicos poderosos, carregados com morfina ou derivados. Ela não quis viver os seus últimos dias com alucinações, semiconsciente, sem capacidade de raciocínio, sem emoções para dar ou receber, com o cérebro entorpecido e o corpo dormente. (PORTUGAL, 2018).
}

Em Portugal, as diretivas antecipadas de vontade são reguladas pela Lei n. 25/2012, (PORTUGAL, 2012b). Ana Catarina, dias antes de sua morte entregou ao marido o documento, que outorgaria a ele o cumprimento da decisão "pela execução da sua vontade médica quando chegasse a fase terminal da doença" em uma referência ao testamento vital. O depoimento do marido, publicado no Quadro Opinião de um jornal local expõe que "Ana Catarina recusou o excesso de tratamentos porque recusou fingir viver, recusou deixar de ser a Ana Catarina" numa característica muito semelhante ao que pensava Ana Bea. (PORTUGAL, 2018).

Os cuidados paliativos e as diretivas antecipadas de vontade (ou testamento vital) portugueses demonstram um avanço em relação ao Brasil, pois em Portugal já está regulamentado por lei e sua otimização pode servir de exemplo ao Brasil como tão bem sugerido por Lippmann (2015). 
Os portugueses, portanto, antecessores a nós, conceberam em 1995 a Associação Portuguesa de Cuidados Paliativos - APCP, que tem por "finalidades dinamizar as diferentes vertentes ligadas à melhoria da qualidade dos cuidados paliativos e à promoção e desenvolvimento do estudo, investigação e ensino dos cuidados paliativos". (PORTUGAL, 1995). Recentemente, e a partir da experiência verificada ao longo dos anos, o Conselho Nacional de Ética para as Ciências da Vida - CNECV emitiu Parecer a partir do seguinte questionamento: "Devem os profissionais de saúde abordar um doente que se encontre em sofrimento intenso, na fase de internamento, e providenciar-Ihe informação sobre o direito que tem ao testamento vital?" Ao responder o Conselho recomendou que haja "respeito pela vulnerabilidade das pessoas", pois ainda que a todos os pacientes seja dado o direito a conhecer o seu estado clínico, o cuidado com o momento em que o doente está deve ser considerado. (DIÁRIO DE NOTÍCIA, 2017).

O Parecer faz um chamamento aos profissionais de saúde para que reflitam sobre a fragilidade do paciente em ambientes hospitalares e conclui "que o dever dos profissionais de saúde em informar os doentes nesta matéria tem de ser exercido no quadro da relação terapêutica estabelecida com o paciente e não por imposição de uma qualquer norma", reforçando a confiança como instrumento norteador da relação médico-paciente. (DIÁRIO DE NOTÍCIA, 2017).

Um estudo interdisciplinar elaborado pela Universidade de Coimbra, durante 15 anos e divulgado recentemente, revelou que há dois aspectos importantíssimos a serem considerados quando se trata de cuidados paliativos. Segundo Bárbara Gomes a sociedade portuguesa adota um "modelo dual" de cuidados: ${ }^{2}$

Por um lado, há uma tradição de apoio familiar alargado - tenta-se cuidar dos nossos em casa, uma missão que é muito associada às mulheres na família. Por outro lado, somos extremamente dependentes dos hospitais - achamos que lá vamos encontrar os melhores cuidados de saúde.

A docente da Faculdade de Medicina de Coimbra atenta para um modelo "hospitalocêntrico" que contribuiria para Portugal ostentar uma das maiores taxas de mortes hospitalares, principalmente em pacientes mais jovens. Alguns dos tópicos do estudo indicam perspectivas de aumento da longevidade, impactando num período mais longo de adoção de medidas paliativas e, ainda, apontam as necessidades desses cuidados também em pacientes pediátricos. A pesquisa ressalta, por fim, a utilidade de "cuidados paliativos pediátricos com forte apoio domiciliário, que acompanhem as crianças e famílias durante toda

\footnotetext{
2 "No âmbito da investigação, foram analisados dados de mais de um milhão de pessoas falecidas em Portugal entre 1987 e 2012, 'cruzando as perspetivas de especialistas em saúde pública, cuidados paliativos e pediatria, para melhor entender a realidade portuguesa'". In: CUIDADOS paliativos em Portugal são insuficientes - Estudo. Diário de Notícia. Lusa. Publicado em: 24 jan. 2018. Disponível em: <https://www.dn.pt/lusa/interior/cuidados-paliativos-em-portugal-sao-insuficientes---estudo-9070440.html>. Acesso em: 10 maio 2018.
} 
a sua trajetória de vida", estabelecendo-se, desse modo um novo paradigma de adoção de cuidados paliativos em Portugal. (PORTUGAL, 2018).

Assim, a legislação contemplada pela Lei 52/2012, pela Portaria 340/2015, pela Resolução n. ${ }^{\circ}$ 5/2017 e pela Portaria 75/2017, consolidam a preocupação portuguesa, legitimada no Despacho 14.311A/2016, reconhecendo que:

aplicados precocemente, os Cuidados Paliativos trazem benefícios para os doentes e suas famílias, diminuindo a carga sintomática dos pacientes e a sobrecarga dos familiares, reduzindo desta forma os tempos de internamento hospitalar, os reinternamentos, a futilidade terapêutica, o recurso aos serviços de urgência e aos cuidados intensivos e, consequentemente, os custos em saúde. (PORTUGAL, 2016).

Observa-se uma preocupação no tocante à melhoria da qualidade de vida de pacientes em final de vida, mas se evidencia uma dificuldade em compreender pacientes como Ana Beatriz e Ana Catarina, como tão bem assevera o relato do marido de Ana Catarina:

O sistema de saúde não entende doentes que procuram, como ela, diminuir ao mínimo o tempo passado com médicos, exames clínicos, quimioterapias ou salas de espera. A medicina, a farmácia, sabem internar, diagnosticar, receitar, consultar, testar, experimentar, drogar... Um doente que exige estar fora desta indústria é um embaraço. (PORTUGAL, 2018).

A terminalidade da vida desafia o médico, capacitado para salvar vidas, independentemente de sua crença ou ideologia, seja no Brasil ou em Portugal, a um dever de cuidado e de respeito à vontade do paciente, ratificando, conforme manifestam-se a doutrina e o judiciário, que não há conflito em respeitar o direito à vida e em renunciar a tratamentos fúteis que prolonguem inutilmente o sofrimento.

Relativamente aos cuidados paliativos, os estudos, na busca do aprimoramento do conhecimento e de sua efetiva implementação, bem como as diretrizes do Conselho Federal de Medicina e os julgados brasileiros, retrataram uma harmonia tanto em relação aos posicionamentos quanto à mantença da autonomia e da vontade do paciente. A autonomia da relação médico-paciente foi enfatizada a partir de estudo de caso envolvendo uma paciente, Ana Beatriz, de 60 anos, em final de vida. Com o mesmo objetivo, considerou-se o caso de Ana Catarina, cuja investigação assinalou que em Portugal ocorreu um avanço em relação ao Brasil, pois o Testamento Vital foi otimizado com a criação do RENTEV, um banco de dados para consulta pelos médicos nos casos de urgência e emergência. Revelou-se que é latente em Portugal a discussão não somente quanto ao respeito à autonomia, mas também quanto ao nível de empatia e de sensibilidade atinente aos pacientes internados. 
Convém ainda registrar que os cuidados continuados integrados demonstram a preocupação do Estado português com o envelhecimento da população e, consequentemente com políticas públicas que amparem pessoas com doenças crônicas incapacitantes, pessoas idosas com dependência funcional e de pessoas com doenças incuráveis em final de vida. Portanto, a partir da análise dos cuidados paliativos, constatou-se que a terminalidade da vida desafia o médico, capacitado para salvar vidas, independentemente de sua crença ou ideologia, seja no Brasil ou em Portugal, a um dever de cuidado e de respeito à vontade do paciente, ratificando, conforme manifestaram-se a doutrina e o judiciário, que não há conflito em respeitar o direito à vida e em o paciente renunciar a tratamentos fúteis que prolonguem inutilmente o sofrimento.

\section{CONCLUSÃO}

Os códigos de conduta médica do Brasil e Portugal detêm poder de penalização infralegal e a legislação civel e penal responsabiliza aquele profissional médico que não se utilizou corretamente de todas as possibilidades da ciência, na busca da cura ou da reabilitação do paciente e condena aquele que não agiu com zelo e atenção do desempenho da profissão, enfocando as características da natureza jurídica em ambos os países.

No que diz respeito à relação médico-paciente, constatou-se que o paciente tem o direito de conhecer o diagnóstico, a terapêutica e o prognóstico de sua doença ao encontro do que preconizam os códigos de conduta médicos examinados.

Relativamente aos cuidados paliativos, as diretrizes do Conselho Federal de Medicina e os julgados brasileiros, retratam uma harmonia tanto em relação aos posicionamentos quanto à mantença da autonomia e da vontade do paciente. A autonomia da relação médico-paciente foi enfatizada a partir de estudo de caso envolvendo uma paciente, Ana Beatriz, de 60 anos, em final de vida. Com o mesmo objetivo, considerou-se o caso de Ana Catarina, cuja investigação assinalou que em Portugal ocorreu um avanço em relação ao Brasil, pois o Testamento Vital foi otimizado com a criação do RENTEV, um banco de dados para consulta pelos médicos nos casos de urgência e emergência. Revelou-se que é latente em Portugal a discussão não somente quanto ao respeito à autonomia, mas também quanto ao nível de empatia e de sensibilidade atinente aos pacientes internados.

A pesquisa mostrou que em Portugal há uma grande preocupação com os cuidados paliativos consagrada por um aparato legal constituído por Resoluções, Portarias e Despachos, em que são normatizadas questões que vão desde instalações específicas à profissionais qualificados para esse fim. Chamou a atenção que, pela Resolução da Assembleia da República n. 5/2017, as faculdades de 
Medicina são obrigadas a integralizarem em seus currículos o tratamento das questões pertinentes a cuidados paliativos. Esta Resolução sinaliza claramente a necessária internalização desta temática já na graduação para que o futuro médico seja habilitado a trabalhar com os conflitos e dificuldades que permeiam os cuidados paliativos. Além do exposto, merece destaque a vontade portuguesa em olhar com carinho e cuidado os doentes terminais pelo Aviso n. 15.263/2017 que abre concurso para vagas para o ciclo de estudos especiais de Cuidados Paliativos no Adulto, com início previsto para o ano 2018, reiterando que para uma sólida formação dos médicos é necessária a boa prática da medicina paliativa.

\section{REFERÊNCIAS}

ASSOCIAÇÃO MÉDICA MUNDIAL (AMM) Declaração sobre eutanásia. Madrid, 1987. Disponível em: <https://www.ufrgs.br/bioetica/madrid.htm>. Acesso em: 30 out. 2018.

BEAUCHAMP, T. L.; CHILDRESS, J. F. Princípios de Ética Biomédica. 3. ed, São Paulo: Edições Loyola Jesuítas, 2013.

BELTRÃO, S. R. O Consentimento Informado e sua Dinâmica na Relação Médico-Paciente: Natureza Jurídica, Estrutura e Crise. Cadernos do Programa de Pós-Graduação Direito UFRGS. Porto Alegre, v. 9, n. 2, 2014. Disponivel em: <http://seer.ufrgs.br/index.php/ppgdir/article/view/50162>. Acesso em: 24 out. 2018.

BOTTEGA, C.; CAMPOS, L. S. F. Considerações sobre Eutanásia, Distanásia e Ortotanásia e a Bioética. Disponivel em: <http://www.clarissabottega.com/Arquivos/Artigos/Artigo\%20Clarissa\%20Bottega\%20 eutan\%C3\%A1sia\%20e\%20a\%20bio\%C3\%A9tica.pdf>. Acesso em: 08 nov. 2018.

BRASIL. Constituição (1988). Constituição da República Federativa do Brasil de 1988. Disponível em: <http://www.planalto.gov.br/ccivil_03/constituicao/constituicao.htm>. Acesso em: 06 nov. 2018.

CASADO, M.; ROYES, A. (Coords.) Documento sobre la disposición de la propia vida en determinados supuestos: declaración sobre la eutanásia. Barcelona. Elaborado por el Grupo de Opinión del Observatori de Bioètica i Dret Parc Científic de Barcelona. Barcelona: Universidad de Barcelona, 2003. Disponivel em: <https://www.eutanasia.ws/_documentos/dossier_eutanasia/declaraciones_ espa\%C3\%B1a/03\%200BD\%20declaraci\%C3\%B3n\%20eutanasia.pdf>. Acesso em: 30 out. 2018. 
CERISARA, A. B. Estou pronta para morrer. Veja. Youtube. 17 dez. 2017. 11min37s. Disponível em: <https://www.facebook.com/Veja/videos/10155648927620617/ >. Acesso em: 05 out. 2018.

CLOTET, J.; FRANCISCONI, C. F.; GOLDIM, J. R. Consentimento informado e a sua prática na assistência e pesquisa no Brasil. Porto Alegre: EDIPUC, 2000.

CONSELHO FEDERAL DE MEDICINA. Código de Ética Médica. Resolução CFM n 1.931, de 17 de setembro de 2009. Disponível em: <https://portal.cfm.org.br/images/stories/biblioteca/codigo\%20 de\%20etica\%20medica.pdf>. Acesso em: 14 out. 2018.

. Resolução CFM n 1.995/2012. Dispõe sobre as diretivas antecipadas de vontade dos pacientes. Disponível em: <http://www.portalmedico.org.br/resolucoes/cfm/2012/1995_2012.pdf>. Acesso em: 21 nov. 2018.

FONSECA, P. H. C.; FONSECA, M. P. Direito do Médico - De acordo com o Novo CPC. Belo Horizonte: D’Plácido, 2016.

FORTES, P. A. C. Ética e saúde: questões éticas, deontológicas e legais, tomada de decisões, autonomia e direitos do paciente, estudo de casos. 3. reimpressão. São Paulo: EPU, 2007.

GOLDIM, J. R. Bioética: origens e complexidade. Revista HCPA, Porto Alegre, v. 26, n², p. 86-92, 2006. Disponível em: <https://www.ufrgs.br/bioetica/complex.pdf>. Acesso em: 23 nov. 2018.

. Comentários ao Novo Código de Ética Médica. Palestra proferida na Academia SulRiograndense de Medicina no dia 26 set. 2010. Porto Alegre, 2010. Disponível em: <www.bioetica. ufrgs.br>. Acesso em: 18 mar. 2018.

JUNGES, J. R. et al. Reflexões legais e éticas sobre o final da vida: uma discussão sobre a ortotanásia. Revista Bioética, v. 18, n. 2, p. 275 - 288, 2010. Disponivel em: <http://www.redalyc.org/ html/3615/361533253003/>. Acesso em: 08 abr. 2018.

LIPPMANN, E. Lições de Portugal sobre testamento vital e propostas para regulamentação aqui. Consultor Jurídico, 2015.Disponível em: <www.conjur.com.br/2015-set-06/ernesto-lippmann-licoesportugal-testamento-vital>. Acesso em: 05 abr. 2018.

MATIELO, F. Z. Responsabilidade Civil do Médico. Porto Alegre: Sagra Luzzatto, 1998. 
MÉDICOS devem evitar falar do testamento vital a pacientes internados. Parecer. Diário de Notícia. Sociedade. Publicado em: 24 mar. 2017. Disponivel em: <https://www.dn.pt/sociedade/interior/medicos-devem-evitar-falar-do-testamento-vital-a-doentes-internados-5745671.html>. Acesso em: 12 maio 2018.

MUÑOZ, D. R.; FORTES, P. A. C. O princípio da autonomia e o consentimento livre e esclarecido. In: COSTA, Sérgio Ibiapina Ferreira; GARRAFA, Volnei. Iniciação à Bioética. Brasília: Conselho Federal de Medicina, 1998, p. 53-70.

PINA, J. A. R. E. Ética, deontologia e direito médico. Lisboa: Lidel, 2013.

PITHAN, L. H.. O consentimento informado no Poder Judiciário brasileiro. Revista da AMRIGS.

Porto Alegre, v. 56, n. 1, p. 87-92, jan./mar. 2012. Disponivel em: <http://www.amrigs.org.br/ revista/56-1/0000095683-17_1000.pdf>. Acesso em: 14 out. 2018.

PORTUGAL. 1995. Associação Portuguesa de Cuidados Paliativos. Estatutos. Disponível em: <http:// www.apcp. com.pt/>. Acesso em: 11 nov. 2018.

2009. Ordem dos Médicos. Código Deontológico da Ordem dos Médicos. Disponivel em: <http://www.arslvt.min-saude.pt/uploads/writer_file/document/65/08-2009.pdf >. Acesso em: 22 nov. 2018.

2012a. Diário da República Eletrônico. Lei 52/2012, de 05 de setembro de 2012. Disponível em: <https://dre.pt/pesquisa/-/search/174841/details/maximized>. Acesso em: 15 nov. 2018.

. 2012b. Assembleia da República. Lei n. 25/2012, de 16 de julho de 2012. Disponível em: <http://testamentovital.com.br/legislacao/portugal/>. Acesso em: 05 nov. 2018.

_ _ _ _ - . 2014. Tribunal da Relação de Évora. Acórdão. Recurso Penal n²003/11.0TAPTM.E1. Relatora Juíza Maria Isabel Alves Duarte. Data do julgamento: 29 abr. 2014. Disponível em: <http:// direitodamedicina.sanchoeassociados.com/arquivo/acordao-do-tribunal-da-relacao-de-evoraprocesso-200311-0taptm-e1-violacao-de-segredo-segredo-medico-danos-nao-patrimoniais/>. Acesso em: 24 nov. 2018.

2015. Diário da República Eletrônico. Portaria n 340, de 08 de outubro de 2015. Disponível em: <https://dre.pt/application/conteudo/70485726>. Acesso em: 15 nov. 2018. 
2016. Diário da República Eletrônico. Despacho n 14.311-A/2016, de 28 de novembro de 2016. Disponivel em: <https://dre.pt/home/-/dre/105263926/details/maximized?serie=II\&parte_ filter=31\&day=2016-11-28\&date=2016-12-01\&dreld=105263924>. Acesso: em 15 nov. 2018.

, 2017a. Diário da República Eletrônico. Portaria n 75/2017, de 22 de fevereiro de 2017. Disponivel em: <https://dre.pt/home/-/dre/106509197/details/maximized>. Acesso em: 15 nov. 2018. 2017b. Diário da República Eletrônico. Resolução da Assembleia da República n. 5, de 04 de janeiro de 2017. Disponível em: <https://dre.pt/web/guest/pesquisa/-/search/105679762/details/ maximized?print_preview=print-preview>. Acesso em: 15 nov. 2018.

2017c. Diário da República Eletrônico. Aviso n 15.263/2017, de 19 de dezembro de 2017. Disponivel em: <https://dre.pt/home/-/dre/114380175/details/maximized?serie=Il\&parte_ filter=35\&day=2017-12-19\&date=2017-12-01\&dreld=114366018>. Acesso em: 15 nov. 2018.

. 2018. Seria capaz de matar Ana Catarina? Diário de Notícias. Opinião. Publicado em 29 maio 2018. Disponivel em: <https:/www.dn.pt/opiniao/opiniao-dn/pedro-tadeu/interior/seria-capaz-de-matara-ana-catarina-9387870.html?utm_source=Push\&utm_medium=Web>. Acesso em: 29 nov. 2018.

PRETEL, Marina. Da responsabilidade civil do médico - a culpa e o dever de informação. Conteúdo Jurídico, 31 maio 2010. Disponivel em: <http://www.conteudojuridico.com.br/?colunas\&colunista=151 Mariana_Pretel\&ver=641 >. Acesso em: 29 out. 2018.

RIO GRANDE DO SUL. 2011. Tribunal de Justiça do Rio Grande do Sul (TJRS). Apelação Cível n 70042509562. Relator Desembargador Armínio José Abreu Lima da Rosa. Data do Julgamento: 01 jun. 2011. Disponivel em: <http://www.tjrs.jus.br/busca/search?q=\&proxystylesheet=tjrs_index\&client=tjrs_ index\&filter $=0 \&$ getfields $={ }^{*} \& a b a=$ juris\&entsp $=a_{-}$_politica-site $\& w c=200 \& w c \_m c=1 \& o e=U T F-$ 8\&ie=UTF-8\&ud=1\&sort=date\%3AD\%3AS\%3Ad1\&as_qj=\&site=ementario\&as_epq=\&as_oq=\&as_ eq=\&partialfields=n\%3A70065995078\&as_q=+\#main_res_juris>. Acesso em: 06 nov. 2018.

2013. Tribunal de Justiça do Rio Grande do Sul (TJRS). Agravo de Instrumento n 70065995078. Relator Desembargador Sergio Luiz Grassi Beck. Data do Julgamento: 03 set. 2013. Disponivel em: <http://www.tjrs.jus.br/busca/search?q=\&proxystylesheet=tjrs_index\&client=tjrs_ index\&filter $=0$ \&getfields $={ }^{*} \& a b a=$ juris\&entsp $=a_{-}$_politica-site $\& w c=200 \& w c \_m c=1 \& o e=U T F-$ 8\&ie=UTF-8\&ud=1\&sort=date\%3AD\%3AS\%3Ad1\&as_qj=\&site=ementario\&as_epq=\&as_oq=\&as_ eq=\&partialfields=n\%3A70065995078\&as_q=+\#main_res_juris>. Acesso em: 06 nov. 2018. 


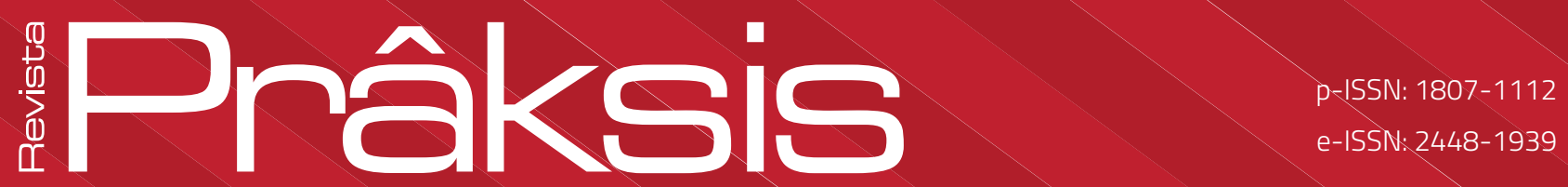

SANCHO, Marcos Gómez. Morir com dignidad. Revista Prática Hospitalar. São Paulo, ano II, n. 9, p. 5461, maio/jun. 2000.

SÃO PAULO. 2009. Tribunal de Justiça do Estado de São Paulo. Apelação 994080424203. Relatora Desembargadora Donegá Morandini. Data do Julgamento: 15 dez. 2009. Disponível em: <https:// esaj.tjsp. jus.br/cjsg/resultadoSimples.do;jsessionid=02FDFFCD3D064C1C19B38A048D70F6A4. cjsg1?conversationld=\&nuProcOrigem=Apela\%C3\%A7\%C3\%A30+994080424203\&nuRegistro=>. Acesso em: 28 out. 2018.

SILVA, Ronaldo Correa Ferreira da; HORTALE, Virginia Alonso. Cuidados paliativos oncológicos: elementos para o debate de diretrizes nesta área. Caderno Saúde Pública, v. 22, n. 10, out. 2006. Disponível em: <www.scielo.br/pdf/csp/v22n10/04.pdf>. Acesso em: 16 nov. 2018.

VALLS, Álvaro Luiz Montenegro. Da ética a bioética. Petrópolis: Vozes, 2004.

VIANNA, Jayme Augusto Rocha; ROCHA, Lys Esther. Comparação do código de ética médica do Brasil e de 11 países. Rev. Assoc. Med. Bras, São Paulo, v. 52, n. 6, p. nov./dez. 2006. Disponível em: <http:// www.scielo.br/scielo.php?script=sci_arttext\&pid=S0104-42302006000600025>. Acesso em: 06 mai. 2018.

VILLAS-BÔAS, Maria Elisa. A ortotanásia e o Direito Penal brasileiro. Revista Bioética, v.16, n.1, p. 6183, 2008. Disponivel em: <http://www.redalyc.org/html/3615/361533250006/>. Acesso em: 08 nov. 2018.

TWYCROSS, Robert. Medicina Paliativa: Filosofia e Considerações Éticas. Acta Bioethica. Centro Interdisciplinario de Estudios en Bioética, Universidad de Chile, Santiago, 2000, ano VI, n. 1, p. 29-46, 2000. Disponivel em: <https://scielo.conicyt.cl/pdf/abioeth/v6n1/art03.pdf>. Acesso em: 05 nov. 2018. 